\title{
Small forms in the landscape of modern urban city parks
}

\author{
Albina Mokina $^{1 *}$, Anna Mokina $^{1}$, and Evelina Vereshchagina $^{1}$ \\ ${ }^{1}$ Southern Federal University, 105/42, Bolshaya Sadovaya Str., 344006, Rostov-on-Don, Russia
}

\begin{abstract}
Today, the culture of modern parks and landscaping is relevant and rapidly developing. A modern park is not just a green area for recreation in the spatial environment of the city, it is a zone of comfort, aesthetics, ecology, engineering innovations, landscape design, sports and walks, a world of interests, it is a harmony of nature, space, small architectural forms. The article analyzes a number of modern Russian parks from the point of view of the spatial organization, mass and cultural recreation places, the scale of territories and volumes, recreational areas for their intended purpose, landscaping and regional aspects. The author also considers the methods of creating an aesthetically harmonious territory, built with smooth transitions from human-made objects to wildlife. The task is to identify the main trends in the organization of the spatial environment of the city park, taking into account the aesthetics of the architectural complex, to track how effectively regional projects of landscaping are implemented in practice. A modern park is a comfortable public all-year-round universal space.
\end{abstract}

\section{Introduction}

At present, with the increase in the active growth of cities and the development of social, business and industrial zones, the need for an organized system of recreation in the urban structure is increasing. We should not underestimate the role of parks in creating a comfortable environment for people to relax, and therefore, the problem of developing recreational areas in the structure of the city is acute. The lack of recreational landscaping is characteristic of almost all modern large cities. To solve this problem, it is necessary to develop and modernize territories that have recreational significance. The presence and condition of such territories in the structure of the urban environment dictate different approaches to its development and organization. To determine these approaches, it is necessary to understand the established traditions of the park territories organization and modern trends in their formation.

Modern trends in landscaping are considered from the point of view of landscape design and landscaping Agata Zachariasz [1], Diana Dushkova [2], Maria Ignatieva[2], Pauleit, S.a,lEmail Author, Ambrose-Oji, B.bEmail Author, Andersson, E.cEmail Author, Anton, B.dEmail Author, Buijs, A.eEmail Author, Haase, D.f,gEmail Author, Elands, B.eEmail Author, Hansen, R.a,hEmail Author, Kowarik, I.i,jEmail Author, Kronenberg, J.kEmail

\footnotetext{
* Corresponding author: almokina@sfedu.ru
} 
Author, Mattijssen, T.1,mEmail Author, Stahl Olafsson, A.lEmail Author, Rall, E.aEmail Author, van der Jagt, A.P.N.n,oEmail Author, Konijnendijk van den Bosch, C.p [3], Albin Mokina [4] and Evelina Vereshchagina [4]. The interest of researchers lies in the plane of urban planning and architectural problems, urban studies - Valerio Morabito [5], V Dormidontova, A Belkin [6], Alina Pancewicz [7], Li, Xin; Ma[8], Xiaodong; Hu[8], Zongnan [8], issues of park areas design were raised in the studies of N.V. Meseneva [9], N.P. Milova [9], O. O. Smolina [10]. Particularly relevant is the park areas fullness with innovative and engineering technologies [11], including from the point of view of monumental and decorative art, sculptural groups, their scale, theme and harmony [12].

Today's trends allow us to classify parks by area, intensity of use, natural and landscape-genetic features, and purpose. But in any case, the functional content of the park and the social aspect play a key and fundamental role in its organization [13].

Along with the landscape solution, the equipment and the environmental subject content play a key role in the complex project of the entire park territory, since the environment is designed for recreational functions, pedestrian development and unity with the natural context [14]. Small architectural forms (SAFs), large elements of equipment and filling of the environment, along with the architectural volumes of the park have a compositionalforming, accentuated content. Architectural objects on the territory of the park are placed in order to create the most favorable conditions for recreation, entertainment, physical education, etc. Territories near these objects and in their interiors have specific functional equipment related to the subject matter of the object. The linear structure of pedestrian paths is a certain promenade, so the equipment of sites, including viewing platforms, places for photographing, as well as places for organizing contacts of groups of people, places of entertainment, places of recreation. And all these places are key.

The necessary and obligatory elements of park zones are small architectural forms. These ones primarily include the following objects:

- children's playgrounds, which can be solved as whole complexes, or as separate elements, including various carousels, sandboxes, towns, etc.

- sports grounds for different ages (playgrounds, courts, areas with exercise equipment, etc.).

- park furniture (benches, wooden seats, etc.);

- flower beds, vases, trellises for flowers, litter-boxes;

- sculptures, art objects and fountains;

- the lighting elements, the lights, the light composition;

- advertising and information wall units;

- kiosks and pavilions;

- rotundas, decorative bridges, stair complexes;

- support with a decor and a terrace.

In the context of the theme environment of parks, the following categories can be distinguished: size of equipment elements and subject content:

1. Large structures that are the accents of the park and the surrounding area form local and support the main compositional axes, develop certain themes, organize or subordinate large open spaces, often these are objects - administrative buildings that belong to the urban environment rather than directly related to the park.

2. Medium-sized structures of various functional purposes - such as public catering pavilions, pop stages, exhibition halls, and others that have local compositional significance and require coordination in one form or another with the surrounding background.

3. Elements of the architectural and artistic design of the park that enrich the appearance and carry a certain ideological load - sculpture, fountains, some small architectural forms, lighting installations. 
4. Objects that are placed within separate functional zones. These are small volumetric and planar structures, equipment for sports and children's sectors, attractions, retaining walls, stairs and ramp descents. In terms of composition, they are less significant than the previous group of structures.

5. Utilitarian structures scattered throughout the territory - benches, information wall units, kiosks, including mobile ones, fences, utility and technical structures, cloakrooms. Although these objects play a secondary role in the landscape and are compositionally subordinated to natural components and architectural dominants, and other accents, in most cases they have a certain decorative value, stylistically subordinate to the general character of the landscape and park ensemble.

A special role is played by the nature and variety of the texture and pattern of paving pedestrian paths and outdoor areas, setting large-scale and emotional certainty.

The evening condition of all park areas requires a special approach in the concept of selecting the lighting equipment of the environment. This includes the provision of a security system and general light comfort for visitors, decorative effects to identify individual objects such as fountains, sculptures, the identification of natural objects, as well as lighting attractions in certain park areas.

\section{Materials and methods}

In the course of the research, the following methods were used: empirical (study of experience, collection of information, documents and planning decisions, including reference documentation, observation), as well as theoretical (analysis, survey, summary, the method of analogies).

Stages of research

The study took place in several stages: the cumulative and analytical stage, the systematization of the main experience in the improvement of European parks, as well as modern Russian ones, the summary stage.

During the research was examined and analyzed data on several modern park formations in Russia.

\section{1 «Zaryadye» Park}

«Zaryadye» Park is a recreation, entertainment and aesthetic culture zone in the center of Moscow, created from scratch and designed by a team of architects, landscape designers, engineers, lighting and botany specialists (architects from Diller Scofidio + Renfro (New York), specialists from the landscape workshop Hargreaves Associates (New York), and urbanists from Citymakers (Moscow)). In modern design trends, the park attracts visitors from different countries to the world of scientific achievements, introduces them to the nature, culture and history of Russia. According to the concept of the authors of this park space, guests study the features of the flora of different regions of the country, learn about architectural monuments and archaeological highlights, can become spectators of concert programs, visit scientific laboratories, and also become participants in virtual reality.

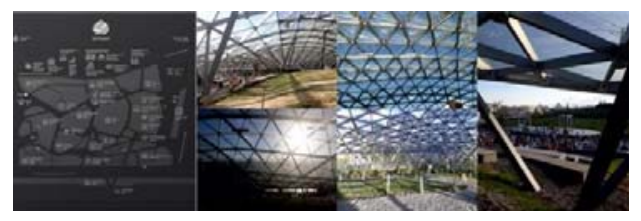

Fig. 1. The schematic map of the park, Source: https://www.artlebedev.ru/zaryadye/navigation/Anna Y. Mokina 
«Zaryadye» is a synthesis of landscape, nature, modern engineering technologies, cultural centers, history, recreation, and entertainment.

The dominant SAFs in «Zaryadye» are the floating bridge and the glass dome-wardiancase (Fig. 1), where a unique collection of Russian exotic plants is gathered. The 70 meter-high concrete consoles of the floating bridge allow visitors to enjoy impressive panoramic views of the Kremlin, Moskva River embankments, the park itself, as well as the center of the capital. Another author's feature of the park is the antiquity and innovation synthesis: cultural heritage objects of the XVI century are adjacent to modern architecture and high-tech attractions.

The main concept of the park, fully realized - is art and science, it is not just a city garden, it is a center of architectural thought, nature and innovative technologies. «Zaryadye» is an iconic landmark of the capital, attracting tourists from all over the world, perceived as a symbol of Moscow, confirming comfort and safety.

\section{2 «Malevich Park»}

The newest park in the Moscow Region, partially opened in 2020. The question arises, why here and why exactly «Malevich». According to some sources, in this forest there is a socalled Malevich oak, near which he rested after a walk and painted pictures. According to the plans, «Malevich Park» in the future will be a thematic art park, filled with exhibition halls, traveling displays and meet the artist events.
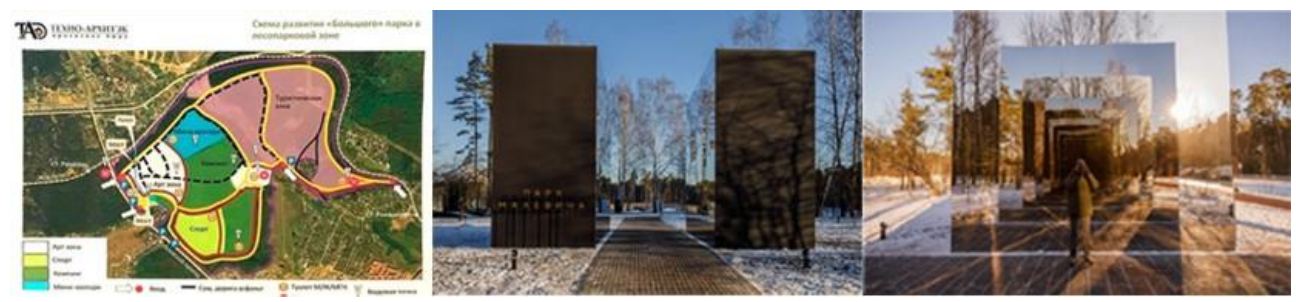

Fig. 2. The schematic map of the park, Source: http://www.press-

release.ru/branches/realestate/blagoustroystvo_parka_malevicha_idet_polnym_khodom_13_07_2020 _16_31/, https://thecity.m24.ru/articles/3679.

«Malevich Park» is an area of 370 hectares, divided into an art zone, a sports zone, a space for tourists, as well as a mini zoo. The main walking paths will be focused on artificial waterfalls, streams and associated landscaping.

But the main centerpiece of the park environment, especially the entrance group, is the SAF-sculpture-art object «Malevich», created by Grigory Orekhov(Fig. 2) . The figurative basis is the famous work of the great avant-garde artist, namely, «Black Square». Embodying a mirror-matte cube in volume, the SAF fits into the environment: the cube divided into two parts in the middle is the entrance group to the park, which gives the art object a function and utility.

\section{3 «Krasnodar Park»}

Galitsky Park (its official name is the park of the Krasnodar football club) is a unique environmental space not only for Krasnodar and the South of the country, but also for Russia as a whole. The project was developed by the German architectural firm GMP International, which previously implemented projects for sports arenas in Krasnodar, Sochi, Berlin, Kiev, as well as in Brazil and South Africa. 
Accents and uniqueness begin with the layout, there are no corners and standard intersections, only spirals and arcs, as well as by changing the heights and building volumes every 50 meters there is a change of views and perspectives, visitors are immersed in a new landscape and picture (Fig.3). A special place in the project is given to the color scheme of landscaping, the work of botanists in the selection of plants is comparable to the projects of interior designers and spatial environment. Color is a powerful visual and emotional aspect of project development: from small visualizations of business cards to monumental developments of the environment [15].

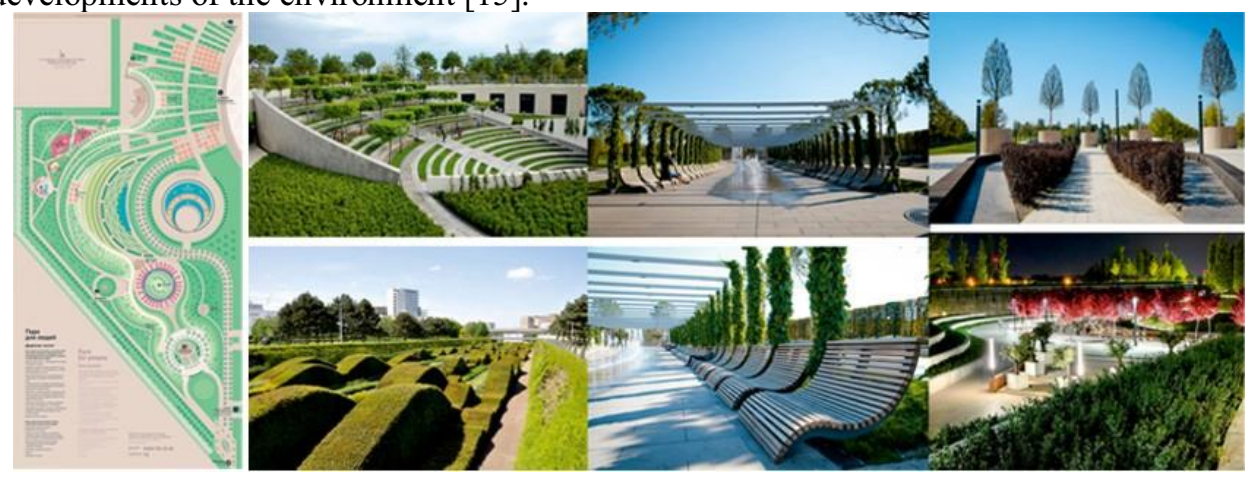

Fig. 3. The schematic map of the park, Source: https://www.artlebedev.ru/fc-krasnodar/park/ Yan Laros

The park's layout includes SAFs: an observation deck, terraces, a fountain that turns into an ice rink in winter, a summer amphitheater, as well as areas for children: rope park, rabbitwarrens, gorodki (scalloping), etc.

The structure of the SAFs literally consists not only of buildings, but also includes areas of relief bushes that form rabbit-warrens, green sculptural surfaces with the topiary art of different heights and, of course, a vegetative amphitheater, designed in the best traditions of ancient architecture, but with modern trends in landscape design (Fig. 3). Also, individual flowerpots-cubes and vases-cylinders for planting trees, connected in composite groups in combination with stair structures, alleys-trellises for flowers in synthesis with fountains and water movement, which is especially important in the summer in the South of the country, complemented by eco-benches, create a single structural space, which are the dominant recreational areas of the park.

In the evening, for the emotional and aesthetic perception of the SAFs, the play of light enters. Innovative approaches in the solution of each recreation area lighting and the unit of the park, «work» in synthesis, complementing and focusing on a particular perspective that opens up to visitors enjoying their vacation.

\section{4 «Loga Park»}

«Loga Landscape Park» is located in a small village «the Old Cossack Village» in $5 \mathrm{~km}$ from Kamensk-Shakhtinsky and $150 \mathrm{~km}$ from Rostov-on-Don. It appeared in 2012, thanks to the initiative of the entrepreneur and philanthropist Sergey Kushnarenko. Thanks to the mutual efforts of architects and landscape designers, the territory of the former garbage dump in Logovaya Balka has now been transformed into a space of garden and park art in the Rostov region. 


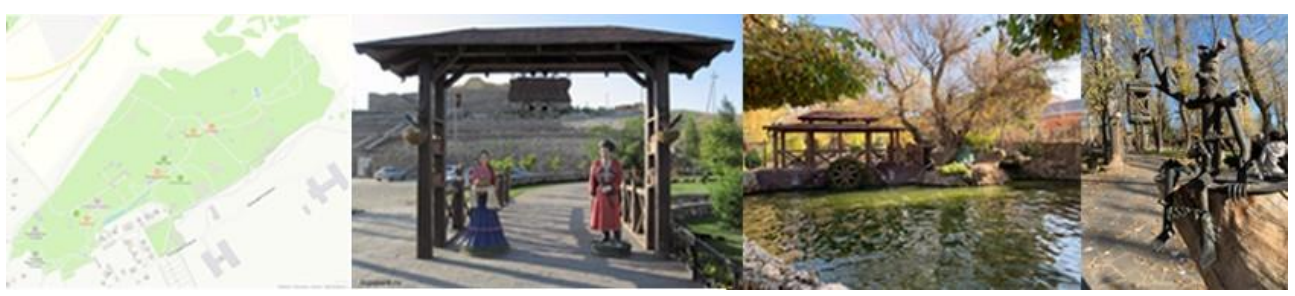

Fig. 4. The schematic map of the park, Source:

https://yandex.ru/maps/?1l=40.297581\%2C48.352227\&source=wizgeo\&utm_medium=mapsdesktop\&utm_source=serp\&z=17, https://logapark.ru/Evelina I. Vereshchagina.

The territory developed gradually from a site of 16 hectares to a modern territory of 22 hectares. Behind the stone walls that surround the entire landscape area of the park, the river, lake and waterfalls are also included. The idea of the Loga Park is to reflect the richness of Russian folklore. The entire site is divided into several thematic zones, such as "Zazerkalie", "Rock Garden", "Lukomorye", poultry yard and zoo, picnic area, children's playground, and there is also a 7-d cinema, restaurant and cafe, souvenir shop, a Ferris wheel is being built and a hotel. More than a hundred unique SAFs and objects of monumental and decorative art are located on the territory of this object: these are sculptures, forged products, bridges, towers, stained glass windows, etc (Fig. 4). As part of the regional aspect, at the entrance to the park, guests are greeted by sculptures of a Cossack and a Cossack woman, which create an appropriate mood for the perception of the entire park space concept in the future. Each zone has its own characteristics, whether it is a special opportunity to perceive the landscape and wildlife, for example, bridges and gazebos, whether it is fabulous sculptures or amazing natural accents, such as images of fairy-tale heroes or amazing stones of various sizes, as well as fancy mirrors that allow you to look at both the landscape and yourself from a different point of view.

All SAFs and products of monumental and decorative art are made by hand in a single copy and copyrighted. Every day, more than 40 people work on the image of the park and its further development in carpentry, blacksmiths, and stained-glass workshops: wood artists, blacksmiths, applied artists, masters of painting and making stained glass.

\section{5 «Suvorovsky Park»}

In 2012, construction of a new residential neighborhood «Suvorovsky» (developer of OOO "VKB-Novostroyki") began on the territory of the Oktyabrsky district of Rostov-onDon, where the park named after the 70th anniversary of the Second World War Victory was laid in 2015. From 2015 to 2019, in addition to planting green spaces in the park, an entrance stele, a monument to the fallen special forces soldiers, landscaping of the pond territory, as well as a bicycle race track were completed.

In 2019, local residents took the initiative, which was supported by the developer and the district administration, to include the park in the Program of arrangement of public territories of Rostov-on-Don city. During the competitive voting, the project of the Ecomonic Partership "Projecting Bureau SREDA" took the first place and entered this Program. 


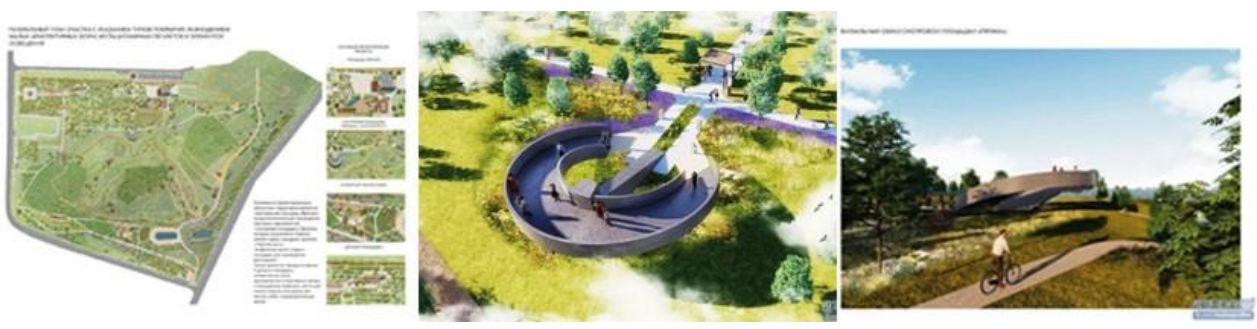

Fig. 5. The schematic map of the park, Source: https://rostovgazeta.ru/news/society/30-10-2020/vnovom-parke-suvorovskogo-poyavyatsya-smotrovye-ploschadki-amfiteatr-i-sad-teney, RostovPositive https://www.facebook.com/rostovpositive/.

The peculiarity of this effort is that in the conditions of modern development of Rostov-onDon, this park is created from 0 , and has no analogues on the territory of the Rostov Region. The main concept of the project authors is the connection of times, from the present to the future, as a result of which there are three main zones-the past, present and future. The past is the perpetuation of the memory of the fallen soldiers, the present is the main square, the name of which was given by the locals as "the Square of Times". The Zone of the future is a training and sports camp with playgrounds for physical education, recreation areas and children's play areas. It is in this zone, where both the younger generation and the older one will train, that the connection of times will take place.

The project provides viewing platforms, where it will be possible to contemplate each zone separately, an amphitheater, where it is planned to hold amazing meetings and thematic events (Fig. 5). Since the main idea of the park is the history of our people, it is also supported in the SAFs and objects of monumental and decorative art. The park will feature sculptures "Scythian Woman", "Sword of Svyatoslav", ships of Peter the Great, figures of grenadiers. In the garden of shadows, the silhouettes of great generals will create an amazing game of light and shadow on the ground. On the territory of the entire park there are benches of various configurations, swings, a navigation system, as well as various containers and bins for separate garbage collections. Originally designed "health path", where the place of rest will be stones.

The implementation period of this project is 2021-2022. It should be noted again that, unfortunately, there are no similar projects for the improvement of eco-territories in Rostov-on-Don today.

\section{Results and conclusions}

After analyzing the most significant modern urban parks in Russia from the point of view of architectural planning and the interaction of landscape and small forms, we can draw the following conclusions:

- landscaping and site improvement is designed out of the purpose of a particular park in interaction with the existing natural situation of the place, region, territory;

- the stylistic and thematic solution of park areas and small architectural forms in them reflect the main components of the city's identity, its culture, innovations, spirituality and, of course, nature;

- during the development of a park zone in an urban environment, it is necessary to think through not only the concept and theme itself, but also to harmonize innovations and aesthetics: the lighting system, the location of paths, recreation areas, playgrounds, landmarks, visual accents and park SAFs. This synthesis allows the implementation of the project on the ground to get high-quality landscaping that corresponds to the time, science, 
culture, as well as the highly artistic idea of harmony between all the elements of designing and decorating the eco-environment.

- a single project work in a team of specialists of different profiles (architects, engineers, botanists, designers, muralists, decorators, etc.) allows you not to ignore any important aspect of creating a comfortable environment in the XXI century.

The results of this research are relevant to use in the training of specialists in the field of architecture, landscape design, monumental and decorative art, as well as engineering.

\section{Reference}

1. A. Zachariasz, IOP Conf. Ser.: Mater. Sci. Eng, 471, 112097 (2019) doi:10.1088/1757899X/471/11/112097

2. D. Dushkova, , M. Ignatieva, Geography, Environment, Sustainability, 13(1), 159-171 (2020)

3. S. Pauleit, B. Ambrose-Oji, E. Andersson, et al., Urban Forestry\& Urban Green, 40, 416 (2019)

4. A. Mokina, E. Vereshchagina, E3S Web of Conferences: INTERAGROMASH 2020, 175, 06006 (2020) doi: 10.1051/e3sconf/202017506006

5. V. Morabito, Archistor-Architecture History Restoration, 12(6), 450-463 (2019), doi: 10.14633/AHR173

6. V. Dormidontova, A. Belkin, IOP Conf. Ser.: Mater. Sci. Eng, 463, 032091 (2018) doi:10.1088/1757-899X/463/3/032091

7. A.Pancewicz, IOP Conf. Ser.: Mater. Sci. Eng., 471, 092037 (2019) doi:10.1088/1757899X/471/9/092037

8. L. Xin, M. Xiaodong, H. Zongnan, et al., Land use policy, 101, 105144 (2021) doi: 10.1016/j.landusepol.2020.105144

9. N.V. Meseneva, N.P. Milova, IOP Conf. Ser.: Mater. Sci. Eng., 463, 022015 (2018) doi:10.1088/1757-899X/463/2/022015

10. O.O. Smolina IOP Conf. Ser.: Mater. Sci. Eng., 962, 032059 (2020) doi:10.1088/1757$899 X / 962 / 3 / 032059$

11. D. T. Budak, O. Semih, B. Serol, Journal of Cleaner Production, 284, 124752 (2021) doi: 10.1016/j.jclepro.2020.124752

12. I. A. Steklova, O. Raguzhina, Vestnik Tomskogo Gosudarstvennogo UniversitrtaKulturologiy I Iskusstvovedenie-Tomsk State University Journal of Cuktural Studies and Art History, 38, 107-124 (2020) doi: 10.17223/22220836/38/11

13. N.V. Polyakova, V. V. Polyakov, V. Y. Zaleshin, Theoretical and Issues of Journalism, 9(2), 363-378 (2020) doi: 10.17150/2308-6203.2020

14. Z. Liang, Journal of Urban Planning and Development, 146(3)(2020) doi: 10.1061/(ASCE)UP.1943-5444.0000576

15. A. Mokina, L. Khoronko, E3S Web of Conferences: INTERAGROMASH 2020, 175, 06006 (2020) doi: 10.1051/e3sconf/202017515008 